\title{
Comparative analysis of fuzzy and ANFIS based MPPT controller for wind power generation system
}

\author{
Annamalai Muthu \\ Department of Electrical Engineering, University of Technology and Applied Science, Nizwa, Oman
}

\begin{tabular}{l}
\hline \hline Article Info \\
\hline Article history: \\
Received Jul 8, 2021 \\
Revised Aug 4, 2021 \\
Accepted Sep 11, 2021 \\
\hline
\end{tabular}

Keywords:

ANFIS

Energy conversion

Fuzzy

MATLAB

Maximum power point tracking

Wind power system

\section{Corresponding Author:}

Annamalai Muthu

Department of Electrical Engineering

University of Technology and Applied Science

Nizwa-Izki Road, PO Box 477 Nizwa, 611 Ad Dakhiliyah, Oman

Email: annamalai.muthu@nct.edu.om
This is an open access article under the CC BY-SA license.

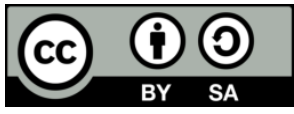

\section{INTRODUCTION}

Today, the application and use of widely developed renewable energy resources due to the growing need for electricity and the inconvenience and difficulties of generating energy through traditional energy sources have paved the way for greater attention to renewable sources in the future [1]. The review articles show that renewable systems are economically highly efficient compared to traditional and traditional fossil power generation systems, but the need for cleaner and quantum energy tends to many improvements in alternative energy generation systems. Electricity, which makes renewable systems the most popular and widely used for many applications [2]. The research sector of the wind energy conversion system (WECS) has seen a lot of participation and analysis for its excellent potential for remote areas for which supplying distribution networks is an uneconomical and cumbersome process for installing the conventional generation system [3]. Among the most popular methods, PMSGs are often chosen for WECS, which act independently because of their greater reliability, lower costs, and more efficient maintenance. Despite the advantages, it is mainly suitable and widely used for variable speed operation, with 10-15\% more efficient power and higher power in watts, less mechanical stress and less power fluctuations than constant speed operation. A PMSG variable speed wind turbine system is more flexible to adapt to sudden changes in the wind [4].

This literature presents a detailed review of past and present MPPT-based controllers applied in the WECS design for maximum power extraction using permanent magnet synchronous generators (PMSG), squirrel-cage induction generators (SCIG), and doubly powered generator induction (DFIG). These controller models can be classified into three main control methods, (a) The tip speed ratio control (TSR) method, (b) The power signal feedback control (PSF) method, and (c) The climb search control (HCS) method. 
The phenomenon of global warming together with the scarcity and lack of availability of fossil fuels have further contributed to motivate the research work towards the generation of renewable electricity and the use of renewable sources. Among the various forms of renewable energy, wind energy has been recognized as the primary and familiar source in the electricity sector. Renewable wind resources for energy production are huge all over the world. Only $10 \%$ of the available wind sources meet the criteria for the use of energy generation established after the assessment [5]. In view of this, the improvement in the performance of wind turbines and WECS is progressively increasing as a trend research sector. Since then, the greater power range of wind turbines, the need to provide a correct interface between the renewable energy generation/conversion system and the electricity grid system for optimal distribution. As a practical solution, methodologies and devices based on power electronics has already been introduced to connect in the literature, several renewable topologies for power conversion schemes were presented. Many types of energy generation conversion systems were commonly used, as in [6] and [7].

Numerous research papers have already proposed a variety of control schemes for optimal energy extraction through WECS [8]. The very simple methodology to find and obtain the maximum power point is based on the PI controller and on the perturb and observe algorithm [9] and [10], but these schemes face a lack of adequate performance. Another well-known technique is the neural network for estimating wind speed from wind energy, the generator speed, which are already measured and, subsequently, controlling the speed of the maximum power generator or the reference value La pair can be derived for the operating point tracker [11] and [12]. Although neural network-based methods ensure rapid response, controller performance fails during the change in the wind system. Furthermore, methods based on fuzzy logic have been widely used because of their better efficacy, as presented in [13] and [14]. On the contrary, the main drawbacks and limitations of these methods are not reliable; lack of stability, uneconomical, according to the analysis of the controller, and the point of maximum power varies in a wide range. The energy-reliability optimization of wind energy conversion system's operation can be achieved by means of the fuzzy sliding mode control [15] and [16].

Numerous literature studies conducted and researched for stability problem analysis and control design are condensed into LMI situations, which can be easily solved using the MATLAB LMI toolbox [17]. The advantage of T-S fuzzy provides an efficient way to design and build the controller [18]. By combining the different linear models, the global system model is derived and achieved. Consequently, the nonlinear controller is once again a general fuzzy combination of each unique linear controller [19]. The power flow modulation and control using the various power system. The efficient usage of power produced is defined. The battery management system is introduced in order to store the excess power produced and use that power in case of power deficiency. The battery management is controlled using the fuzzy logic controller, which is one of the intelligent controllers [20]. The design of the hybrid photovoltaic/wind system and the related battery management system. The fuzzy logic control-based battery management system has been designed for efficient use of energy. The proposed control to operate the charge and discharge mode of the battery during non-linear power generation [21]. A robust control for the wind conversion system based on PMSG and DC / DC boost converter with the aim of maintaining the voltage of the rectified generator at a reference voltage corresponding to the reference power set by the supervisor module. Reference power control is guaranteed without measuring wind speed [22]. Modeling of a three-phase induction generator driven by a horizontal axis wind turbine is described. An adjustable capacitor bank connects to the connection point with a static variation compensator (SVC), which is controlled to regulate the effective voltage. The model obtained is reduced taking into account the dynamics of the system [23] and [24]. As a practical solution, methodologies and devices based on power electronics has already been introduced to connect in the literature, several renewable topologies for power conversion schemes are presented. Many types of energy generation conversion systems are commonly used. The popular conversion topology in the energy sector is the modulated pulse width inverter (PWM) and the six-pulse diode rectifier due to their lower cost and efficiency compared to [25], while this methodology allows the power flow in a sense compared to the backto-back power converter. The back-to- back converter allows a widely used and interesting bidirectional power flow in some applications.

This paper presents a direct design of the MPPT controller for PMSG variable speed wind turbines. In this, the wind generator produces maximum power regardless of the conditions or environmental characteristics of the generator. Independent control algorithm that obtains quick responses for the complex nonlinear system. The main objective and contribution of the paper is comparing the two topologies of fuzzy and ANFIS of the modeling and control strategy of wind turbines is described. The conversion of energy systems based on wind energy has been followed with great attention as a vital source of renewable energy due to the exhaustion and exhaustion of fossil fuel reserves and environmental concerns because of events due to the use of fossil fuels and nuclear energy sources. Although wind energy is abundant, the wind speed varies continuously throughout the day. The amount of energy generated by WECS depends on the tracking 
accuracy of the maximum power points detected by the maximum power point control system (MPPT) of the WECS control system, regardless of the type of wind generator used. The topology of the ANFIS-based converters provided on the machine and on the network, side is analyzed, analyzed by simulating the project proposed in MATLAB to offer the possibility of a bidirectional power flow. The rest of this paper is presented as follows: In the second section, a dynamic modeling of WECS is presented with the importance of the PMSG-based MPPT driver for WECS. The third section begins with fuzzy modeling of the system. Finally, the ANFIS control project is explained and the stability conditions are reported in fourth section. We conclude by presenting the proven results with a detailed discussion with conclusions in the final sections.

\section{MPPT CONTROL METHODS FOR PMSG BASED WECS}

The WECS based on the permanent magnet synchronous generator (PMFG) is widely used because research continues to identify more new projects thanks to its high-power density, greater efficiency, and the possibility of smaller turbine diameter and the availability of high permanent magnet material energy at a reasonably lower price. Numerous research papers were published on the development of the WECS domain for WECS design, which is more efficient, highly reliable, low wear, low noise, compact, and with lower maintenance costs.

Most of the three settings for WECS are used with PMSG machines to convert variable voltage power and variable frequency power into a fixed frequency and a fixed voltage power. Depending on the converter configuration, a particular PMSG WMS with a suitable MPPT controller is designed and developed for your control. Three methods of the MPPT driver algorithm are generally used for WMS PMSG.

\section{FUZZY BASED MPPT}

The proposed fuzzy logic controller has been applied for MPPT by PMSG and has been simulated in various operating conditions, such as wind speed at $5 \mathrm{~m} / \mathrm{s}, 7 \mathrm{~m} / \mathrm{s}, 9 \mathrm{~m} / \mathrm{s}, 11 \mathrm{~m} / \mathrm{s}$, and $12 \mathrm{~m} / \mathrm{s}$. After the simulation, the following results are analyzed to analyze system performance. The fuzzy logic controller has been designed for MPPT controller for wind energy system as presented in Figure 1. The proposed WES is developed in MATLAB environment and analyze its performance under various weather condition. The fuzzy MPPT based WES maximum output power and time take to research maximum power are depicted Figure 2. Finally, the buck converter voltage and current waveform are presented in Figure 3 . Wind power system RMS voltage and current as shown in Figure 4.

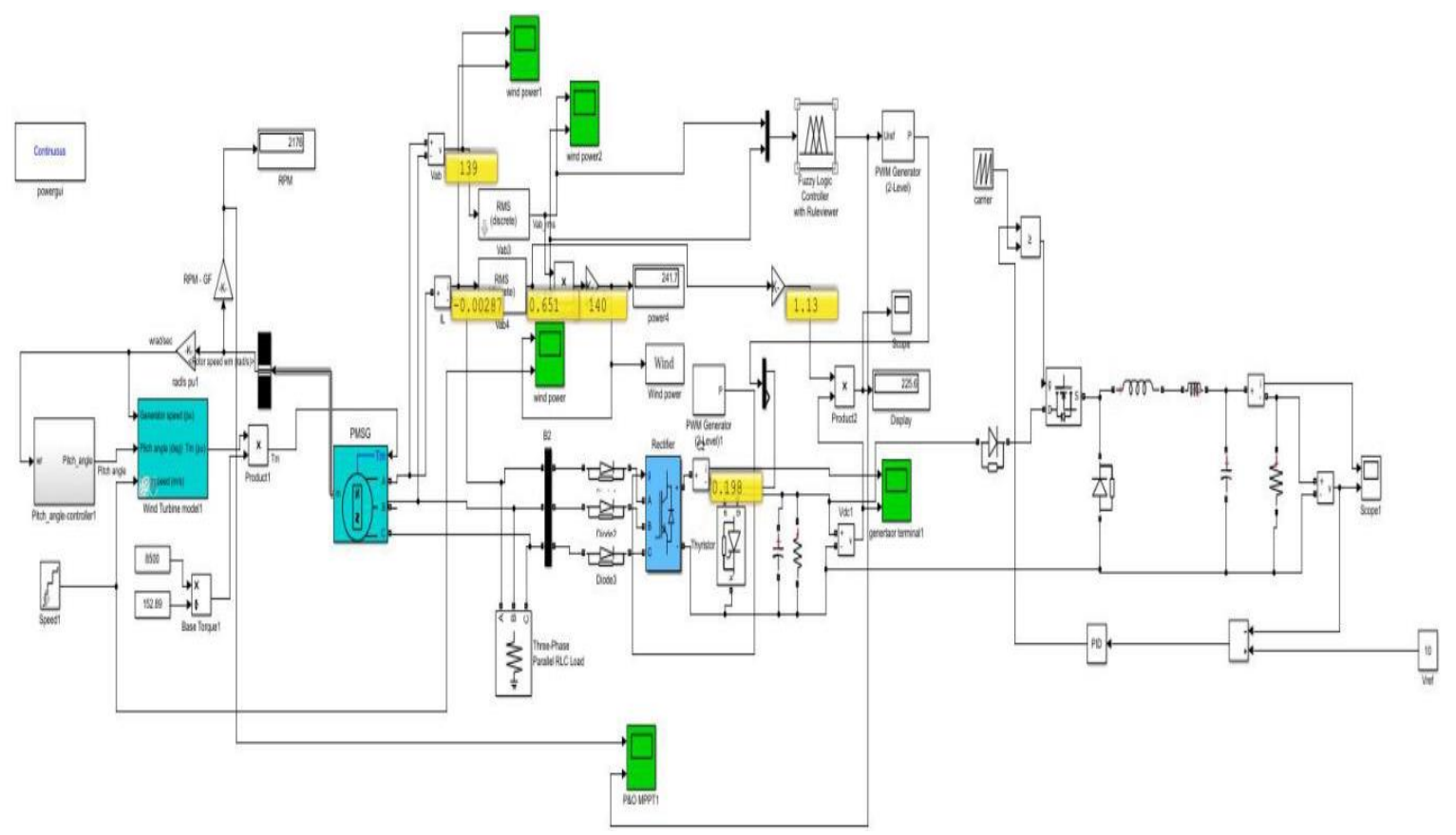

Figure 1. Fuzzy based mppt controller for wes with buck converter for 250 watts wind power system 
In this waveform, the voltage has been maintained as a constant output during unequal power generation of wind power system. In this waveform, the voltage was maintained as a constant output during the irregular generation of energy from the wind system. Drawbacks and limitations of fuzzy based MPPT controllers are sorted out by the hybrid combination of the neural network and fuzzy systems applied to the functionality of the controllers. Neural networks, neuron-based concepts are incorporated into fuzzy systems which can acquire knowledge relevant to the system automatically by executing the learning algorithms for the neural networks. Adaptive neuro-fuzzy inference system (ANFIS), constructs a mapping of input and output in the fuzzy rules form based on human knowledge and on generated input output data pairs by using a hybrid algorithm that is the combination of the least-squares and back propagation gradient descent method.

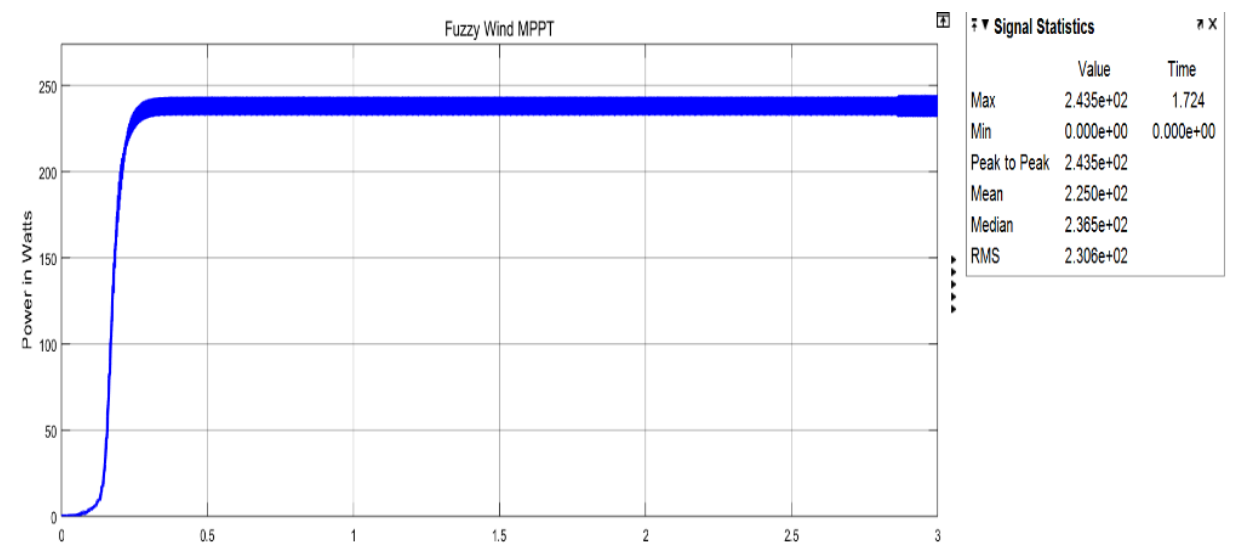

Figure 2. Fuzzy based MPPT controller time taken to reach maximum power
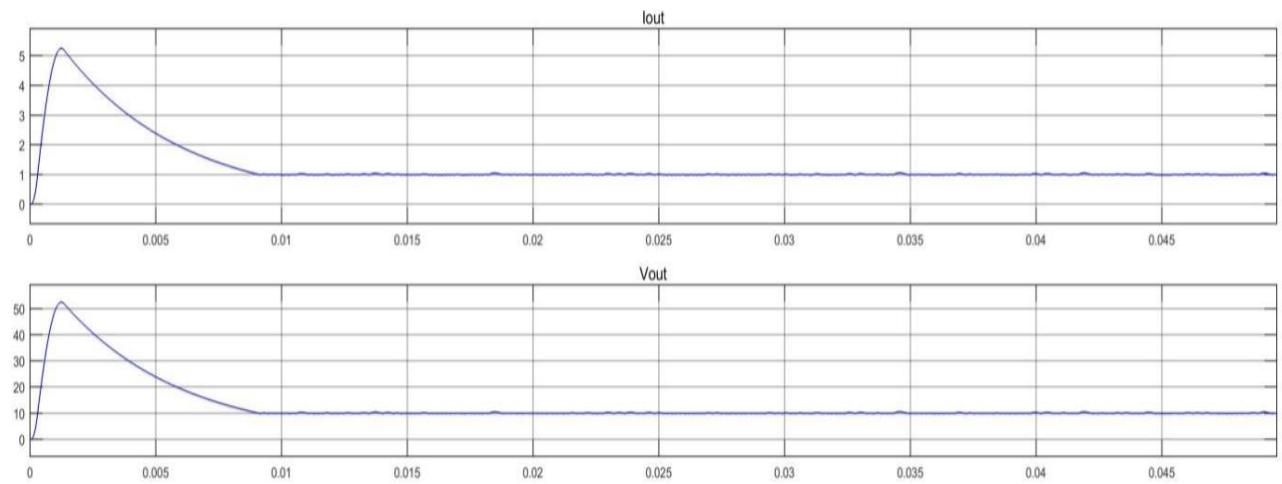

Figure 3. Buck converter O/P regulated voltage and current waveform (fuzzy)
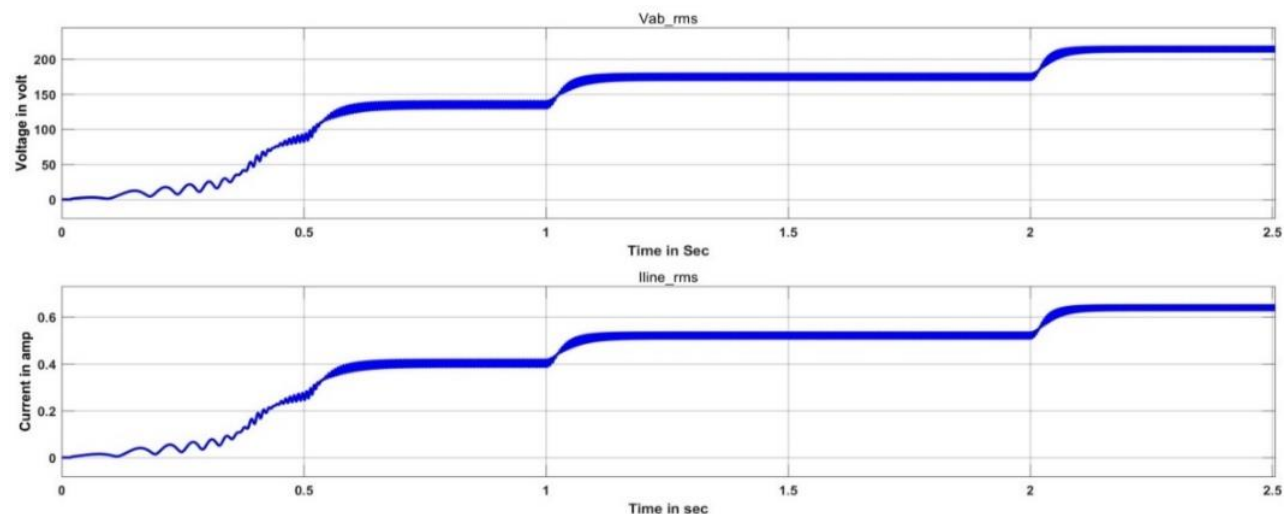

Figure 4. WES RMS voltage and current waveform 


\section{ANFIS BASED MPPT}

Here we present wind speed estimation using ANFIS concepts. ANFIS is regularly trained using least squares inference and the inverse propagation algorithm. Figure 5 shows the ANFIS structure with two inputs and one output. According to the designed model, the ANFIS network could make the decision to estimate the maximum wind speed to be achieved based on the input/output data used for training. The ANFIS controller is designed for the MPPT controller for the wind system, as shown in Figure 6 . The proposed ANFIS MPPT controller has two triangular membership functions at the input, such as a WES voltage input and the second current register. The output of the fuzzy control is the triangular membership function, such as the duty cycle. The ANFIS-based MPPT controller reference model is developed using ANFIS.

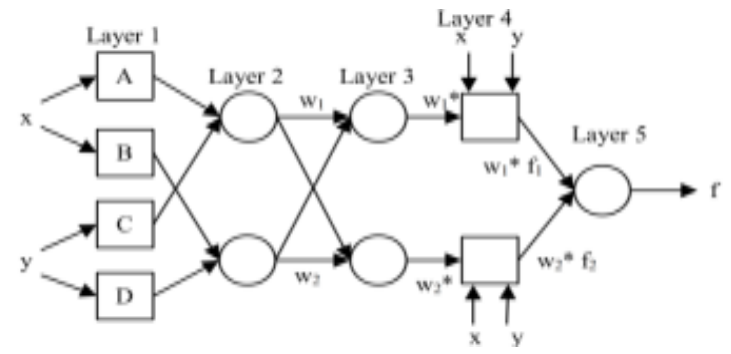

Figure 5. Structure of ANFIS controller

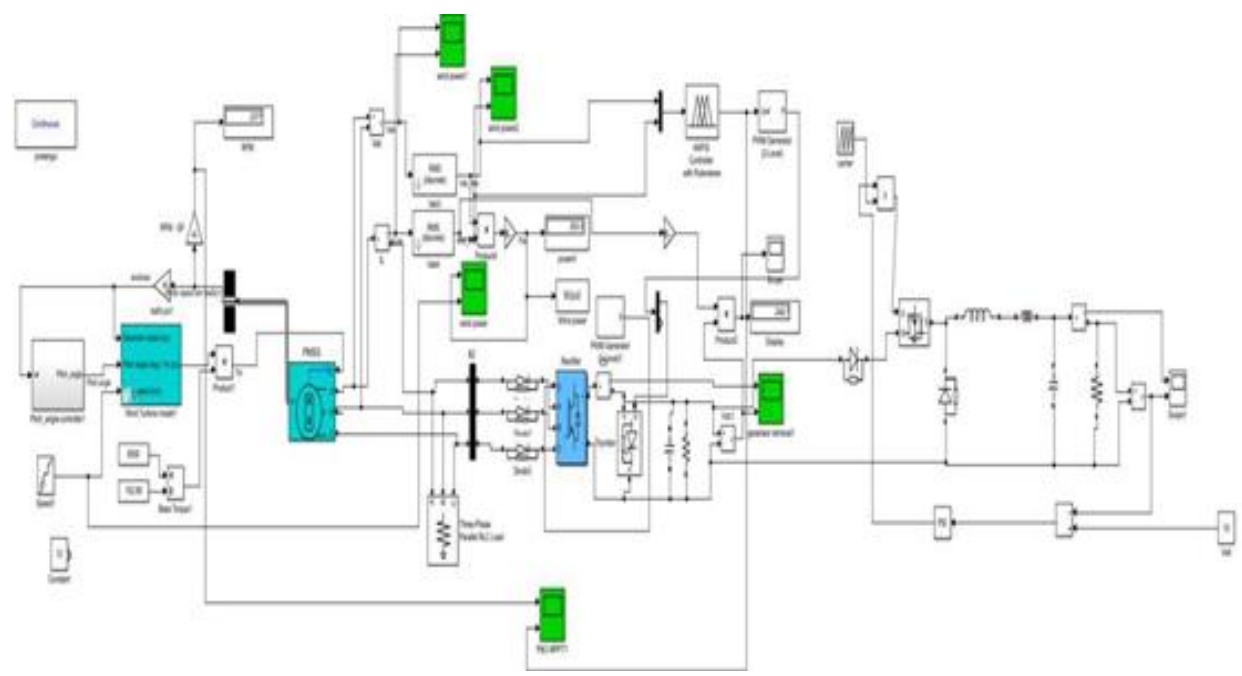

Figure 6. ANFIS based MPPT controller for WES with buck converter for 250 watts wind power system

\section{RESULT AND DISCUSSION FOR ANFIS BASED MPPT CONTROLLER}

The proposed ANFIS controller has been applied for MPPT of PMSG and simulated under various operating condition such as wind speed at $5 \mathrm{~m} / \mathrm{s}, 7 \mathrm{~m} / \mathrm{s}, 9 \mathrm{~m} / \mathrm{s}, 11 \mathrm{~m} / \mathrm{s}$, and $12 \mathrm{~m} / \mathrm{s}$. The after simulation the following results are taken for analysis their system performance such as wind power system RMS voltage and current as depicted in Figure 4. The 250 watts WES output power has been analyzed under wind speed as shown in Figure 6. ANFIS control structure and system-training settings are illustrated in Figure 7 and Figure 8. The ANFIS controller output of training and ANFIS rules are presented in Figure 9 and Figure 10 respectively. The ANFIS controller has been simulated wind power system under standard wind speed as shown in Figure 11 and Figure 12. The ANFIS controller has generated duty cycle with respected to change of wind speed as shown in Figure 13. The fuzzy MPPT based WES maximum output power at various wind speed in Figure 14. Finally, the buck converter voltage and current waveform are presented in Figure 15. In this waveform, the voltage has been maintained as a constant output during unequal power generation of wind power system. The fuzzy and ANFIS controller comparative analysis and performance under various wind speed conditions of 250 watts WES is presented in Table 1. Based on performance the ANFIS controller has been chosen optimum controller for MPPT of WES system. 


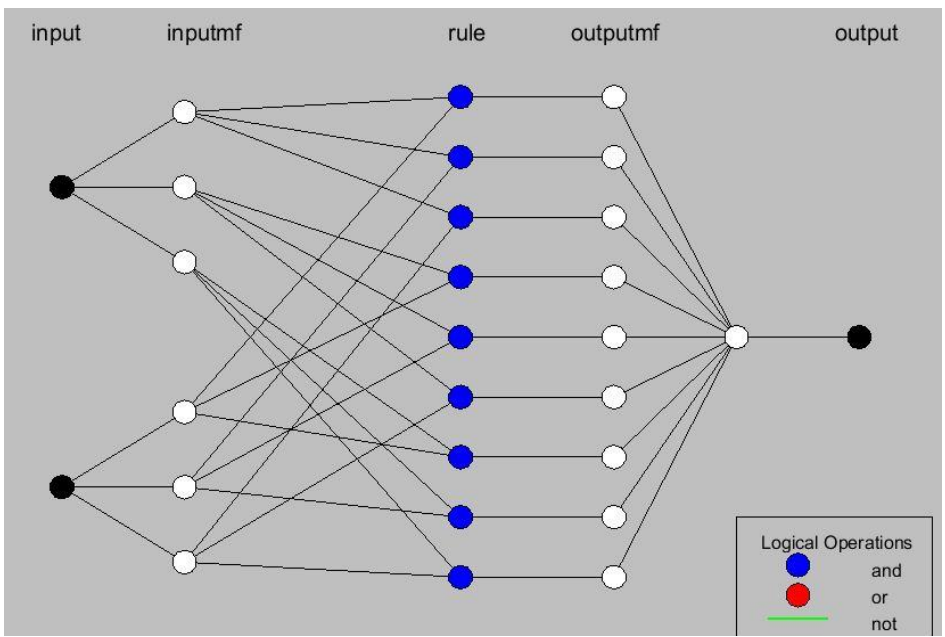

Figure 7. ANFIS MPPT control structure

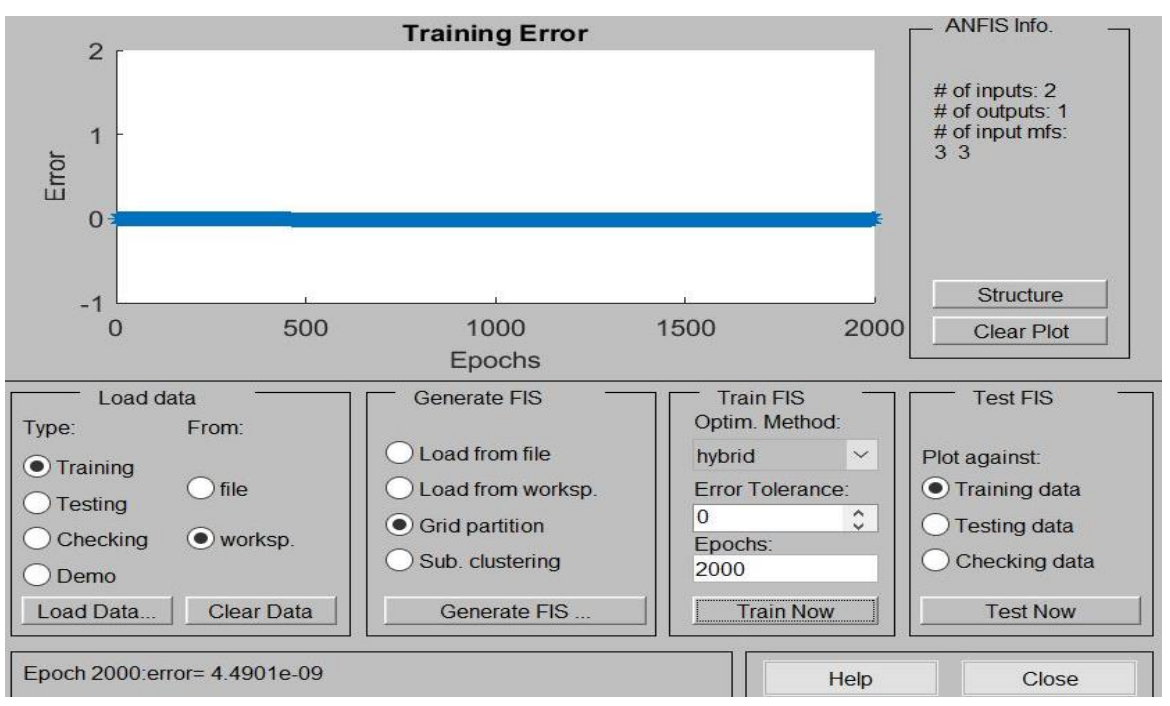

Figure 8. ANFIS control system training

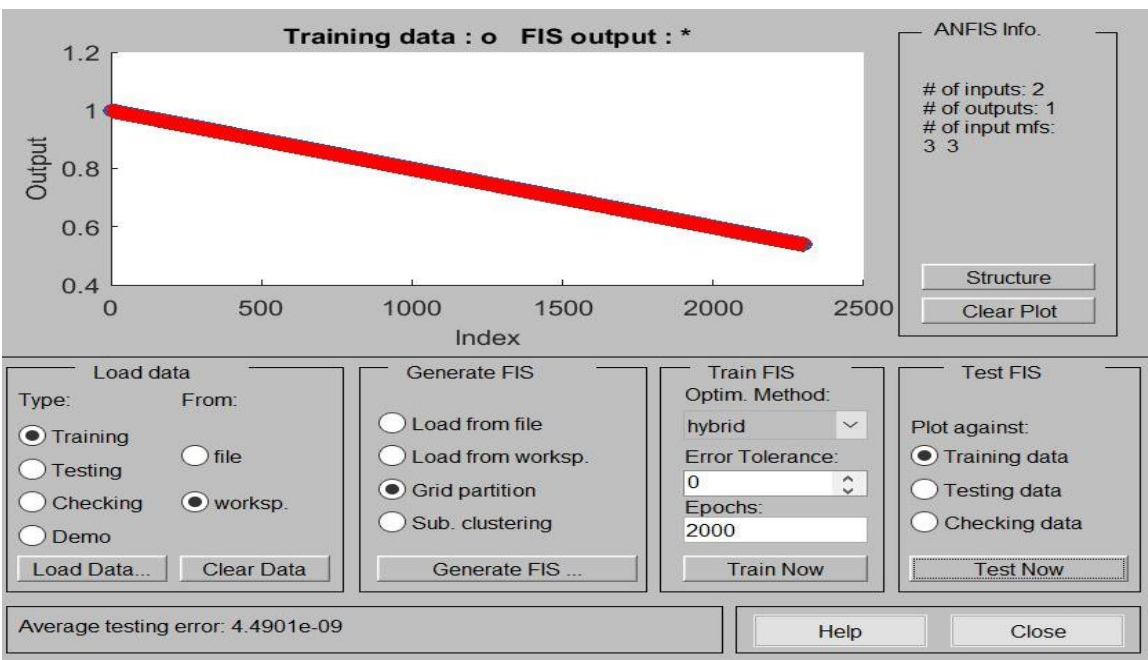

Figure 9. ANFIS control system output 

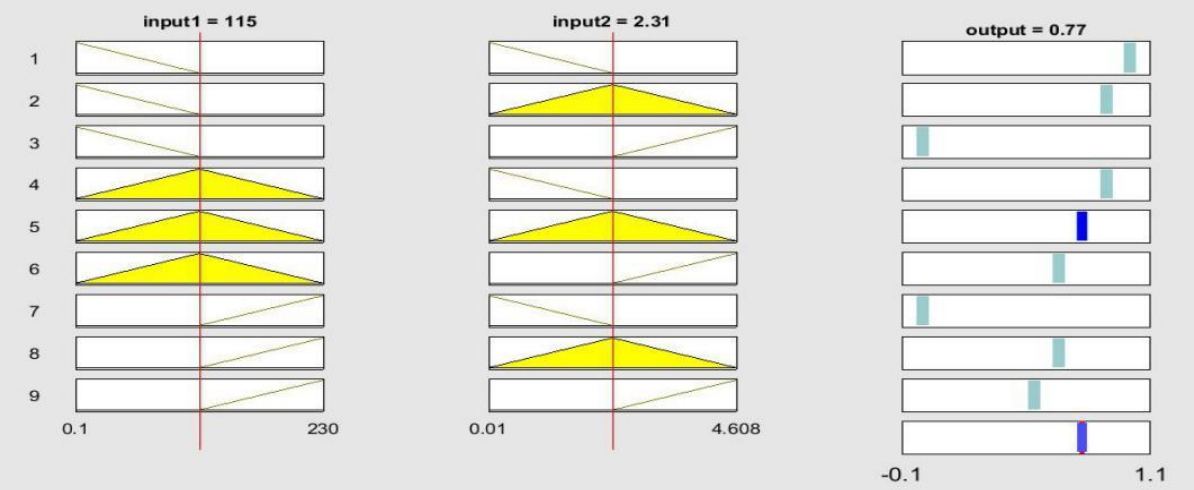

Figure 10. ANFIS control system rules
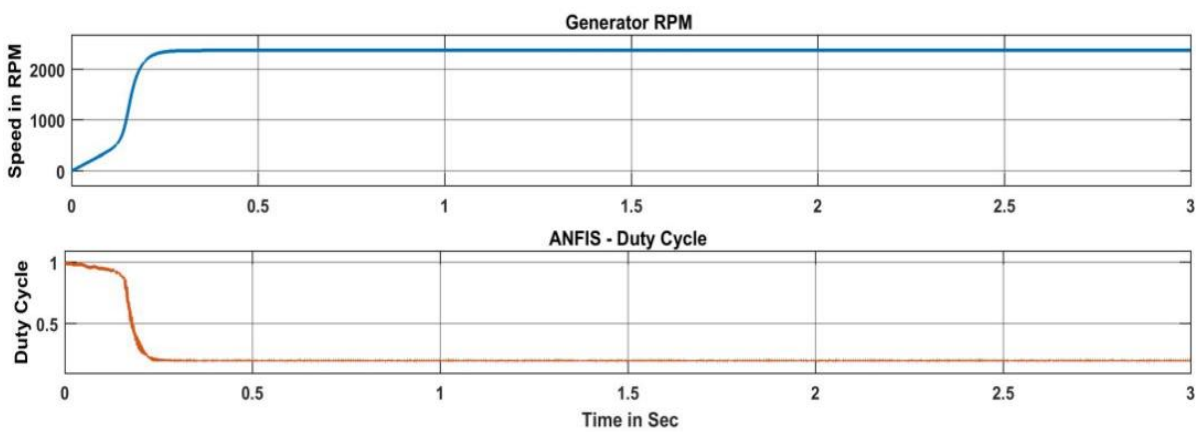

Figure 11. Speed and duty cycle wind power system under standard wind $12 \mathrm{~m} / \mathrm{s}$

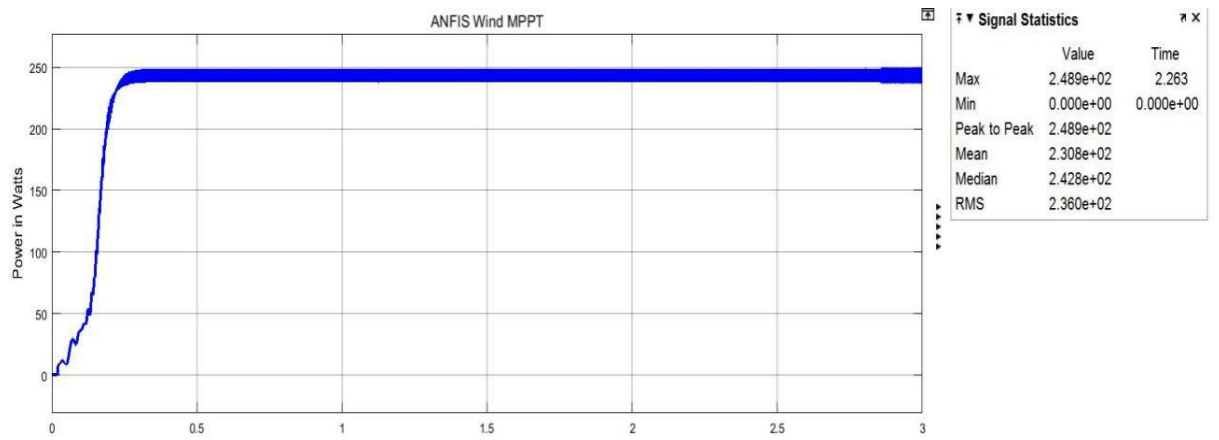

Figure 12. ANFIS based MPPT of wind power system under standard wind $12 \mathrm{~m} / \mathrm{s}$
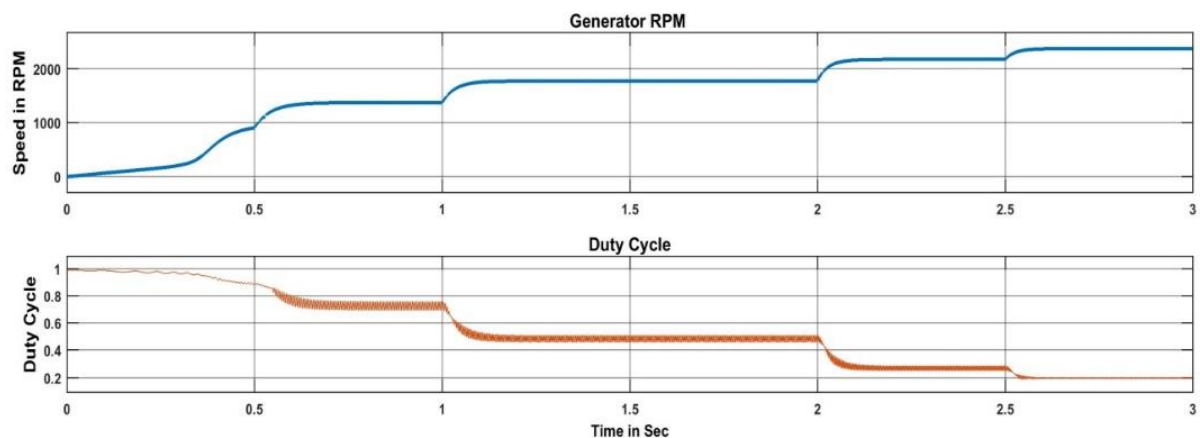

Figure 13. Speed and duty cycle for wind power system under various wind speed 


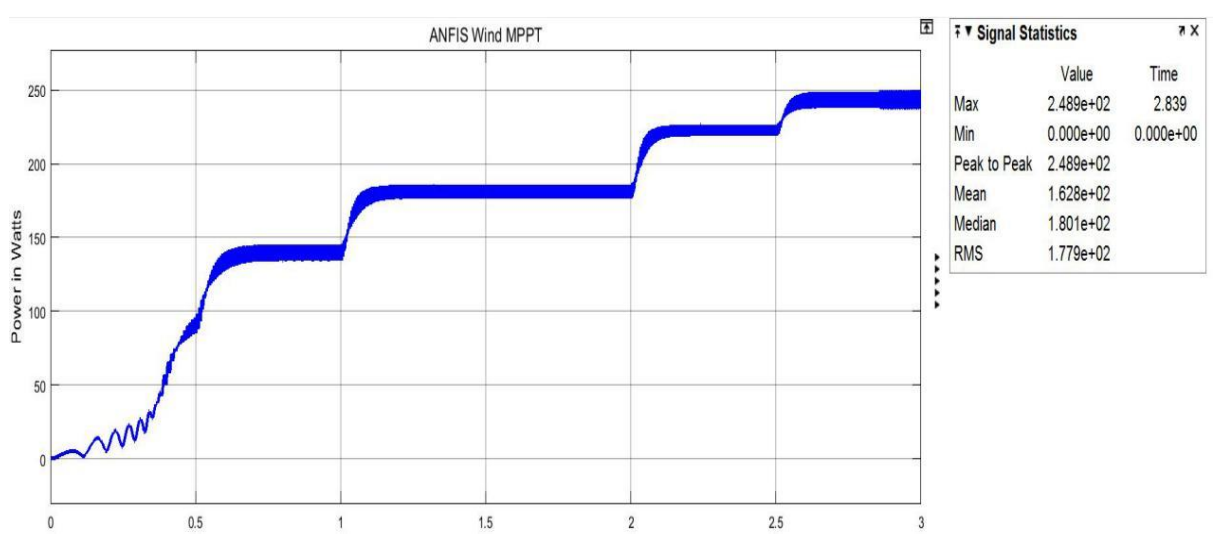

Figure 14. ANFIS based MPPT of wind power system under various wind speed
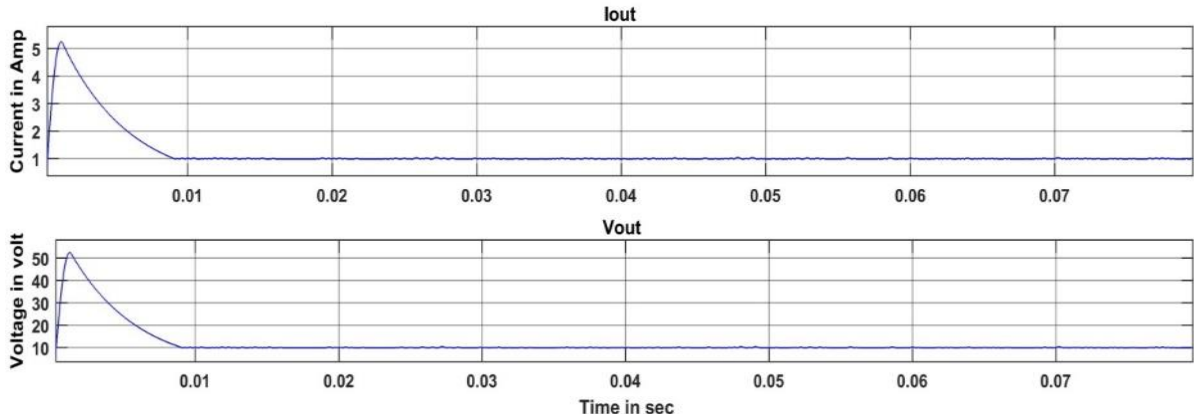

Figure 15. Buck converter O/P regulated voltage and current waveform (ANFIS)

Table 1. Comparison of fuzzy and ANFIS results for 250 watts wind power system

\begin{tabular}{cccc}
\hline S.No & Wind Speed & Fuzzy & ANFIS \\
\hline 1 & $5 \mathrm{~m} / \mathrm{s}$ & $95.6 \mathrm{~W}$ & $95.75 \mathrm{~W}$ \\
2 & $7 \mathrm{~m} / \mathrm{s}$ & $143.5 \mathrm{~W}$ & $144.8 \mathrm{~W}$ \\
3 & $9 \mathrm{~m} / \mathrm{s}$ & $184.6 \mathrm{~W}$ & $185.6 \mathrm{~W}$ \\
4 & $11 \mathrm{~m} / \mathrm{s}$ & $224 \mathrm{~W}$ & $226 \mathrm{~W}$ \\
5 & $12 \mathrm{~m} / \mathrm{s}$ & $243.5 \mathrm{~W}$ & $248.9 \mathrm{~W}$ \\
\hline
\end{tabular}

\section{CONCLUSION}

A wind speed measurement was presented using the ANFIS based MPPT controller for WECS based on variable speed and compared with the existing diffuse based MPPT controller for a 250 watt wind generator system. The simulation-based tabulated values show that ANFIS-based WECS produces more energy efficiently than fuzzy-based WECS MPPT controller does. The proposed ANFIS-based method is analyzed on a WECS variable speed DFEC connected to the network with a backup-to-backup voltage source converter. The ANFIS-based MPPT driver proposed in this paper is verified and applicable to all types of WECS. As an endless determination to create schemes based on MPPT converters to control the speed of the wind generator to maximize energy generation, the methodology based on ANFIS is proposed and the feasibility of the proposed methods is verified by designing a system. The efficient PMFG WECS in the MATLAB and ANFIS controller it is adopted with the system and proven simulated results presented.

\section{REFERENCES}

[1] E. Hau, Wind turbines: fundamentals, technologies, application, economics, Springer Verlag, 2006.

[2] M. Stiebler, Wind energy systems for electric power generation, Springer Verlag, 2008.

[3] M. Dali, J. Belhadj, and X. Roboam, "Design of a stand-alone hybrid Photovoltaic-Wind generating system," Journal of Electrical Systems, vol.4, no. 3, pp. 25, 2008.

[4] R. Mittal, K. Sandu, and D. Jain, "Isolated operation of variable speed driven pmsg for wind energy conversion system," International Journal of Engineering and Technology, vol. 1, pp. 269-273, 2009. 
[5] "Time for action: Wind energy in Europe," European Wind Energy Association, Rome, Italy, Oct. 1991.

[6] H. Le-Huy, P. Viarouge, and J. Dickinson, "Application of power electronics in windmill generation systems," in ENERGEX'82 International Energy Conference, Regina, Canada, 1982, pp. 1080-1088.

[7] T. A. Lipo, "Variable speed generator technology options for wind turbine generators," NASA Workshop, Cleveland, OH, May 1984.

[8] H. M. Nguyen and D. S. Naidu, "Advanced control strategies for wind energy systems: An overview," 2011 IEEE/PES Power Systems Conference and Exposition, 2011, pp. 1-8, doi: 10.1109/PSCE.2011.5772514.

[9] M. Mansour, M. N. Mansouri, and M. F. Mmımouni, "Study and control of a variable-speed wind-energy system connected to the grid," International Journal of Renewable Energy Research (IJRER), vol. 1, no 2, pp. 96-104, 2011.

[10] M. Kesraoui, N. Korichi, and A. Belkadi, "Maximum power point tracker of wind energy conversion system," Renewable Energy, vol. 36, no. 10, pp. 2655-2662, 2011. doi: 10.1016/j.renene.2010.04.028.

[11] H. Li, M. Steurer, K. L. Shi, S. Woodruff, and D. Zhang, "Development of a unified design, test, and research platform for wind energy systems based on hardware-in-the-loop real time simulation," IEEE Trans. on Industrial Electronics, vol.53, no. 4, pp. 3604-3608, doi: 2006. 10.1109/TIE.2006.878319.

[12] A. Meharrar, M. Tioursi, M. Hatti, and A. B. Stambouli, "A variable speed wind generator maximum power tracking based on adaptive neuro-fuzzy inference system," Expert Systems with Applications, vol. 38, no. 6, pp. 7659-7664, 2011, doi: 10.1016/j.eswa.2010.12.163.

[13] M. G. Simoes, B. K. Bose, and R. J. Spiegel, "Fuzzy logic based intelligent control of a variable speed cage machine wind generation system," Proceedings of PESC '95-Power Electronics Specialist Conference, 1995, pp. 389-395 vol.1, doi: 10.1109/PESC.1995.474840.

[14] B. Bahraminejad, M. R. Iranpour, and E. Esfandiari, "Pitch control of wind turbines using IT2FL controller versus T1FL controller," International Journal of Renewable Energy Research (IJRER), vol. 4, no 4, pp. 1077, 2014.

[15] Q. Chen, L. Chen, and L. Wang, "Wind energy conversion systems using fuzzy sliding mode control," 2011 Chinese Control and Decision Conference (CCDC), 2011, pp. 1011-1015, doi: 10.1109/CCDC.2011.5968332.

[16] F. Valenciaga and P. F. Puleston, "High-Order Sliding Control for a Wind Energy Conversion System Based on a Permanent Magnet Synchronous Generator," in IEEE Transactions on Energy Conversion, vol. 23, no. 3, pp. 860867, Sept. 2008, doi: 10.1109/TEC.2008.922013.

[17] D. H. Lee, J. B. Park, and Y. H. Joo, "A new fuzzy lyapunov function for relaxed stability condition of continuoustime takagi-sugeno fuzzy systems," in IEEE Transactions on Fuzzy Systems, vol. 19, no. 4, pp. 785-791, Aug. 2011, doi: 10.1109/TFUZZ.2011.2142315.

[18] C. S. Chiu, Z. H. Li, and Y. H. Chen, "T-S fuzzy direct maximum power point tracking of wind energy conversion systems," International Journal of Fuzzy Systems, vol. 15, no. 2, June 2013.

[19] A. H. Besheer, H. M. Emara, and M. M. Abdel_Aziz, "Fuzzy based output feedback control for wind energy conversion system: an LMI approach," Proc. of IEEE Power Systems Conference and Exposition, 2006, pp. 20302037, doi: 10.1109/PSCE.2006.296237.

[20] M. Venkateshkumar, "Power Flow Management and Control of Hybrid Wind/PV/Fuel Cell and Battery Power System using Intelligent Control," International Journal of Control Theory and Application, vol 9, no. 2, pp. 987995, 2016.

[21] M. Venkateshkumar, "Battery Management System for Hybrid Photovoltaic and Wind Power System using Fuzzy Logic Controller," International Journal of Control Theory and Application, vol 9, no. 2, pp. 1035-1041, 2016.

[22] M. Dahmane, J. Bosche, and A. El-Hajjaji, "Control of Wind Conversion System Used in Autonomous System," Energy Procedia, vol.62, pp. 482-491, 2014, doi: 10.1016/j.egypro.2014.12.410.

[23] A. Boyette, "Contrôle-commande d'un générateur asynchrone à double alimentation avec système de stockage pour la production éolienne," Doctoral dissertation, Université Henri Poincaré-Nancy 1, France, 2006.

[24] L. Krichen, B. Francois, and A. Ouali, "A fuzzy logic supervisor for active and reactive power control of a fixed speed wind energy conversion system," Electric Power Systems Research, vol. 78, no. 3, pp. 418-424, 2008. doi: 10.1016/j.epsr.2007.03.010.

[25] Z. Qiu, K. Zhou, and Y. Li, "Modeling and control of diode rectifier fed PMSG based wind turbine," 2011 4th International Conference on Electric Utility Deregulation and Restructuring and Power Technologies (DRPT), 2011, pp. 1384-1388, doi: 10.1109/DRPT.2011.5994112.

\section{BIOGRAPHY OF AUTHOR}

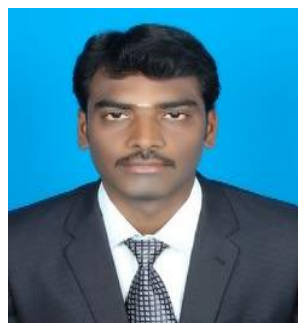

Annamalai Muthu has 17 years of teaching experience. He works as a professor in the Department of Electrical Engineering, University of Technology and Applied Sciences-Nizwa, Oman. His current research areas are optimization techniques, power electronics and drives, application of power electronics in power systems, IOT-based renewable energy systems, and application of power electronics in renewable energy systems. He has published 15 research articles in international journals and 7 articles in international and national conferences. He is a member of the IEEE and a life member of the System Society of India. 